\title{
Desenvolvimento territorial rural: diálogos conceituais
}

\section{Rural territorial development: conceptual dialogues}

\section{Desarrollo territorial rural: diálogos conceptuales}

\author{
Luis Antonio Mello \\ https:/ / orcid.org/0000-0001-5047-2426 \\ luismello2013@gmail.com \\ Universidade Estadual de Ponta Grossa, UEPG, Ponta Grossa, PR
}

Resumo: Este ensaio procura estabelecer um diálogo sobre o termo desenvolvimento e suas implicações na perspectiva da abordagem territorial/rural. Procura também esboçar um breve painel sobre o capital social, redes sociais e associativismo como alternativas à permanência das comunidades rurais em seus territórios. O texto leva em consideração os aspectos socioeconômico e cultural presentes nas obras e autores abordados, bem como, o processo sob a égide do capital, o qual produz e consome espaços e culturas o que parece evidenciar os indivíduos das comunidades em um rural invisibilizado. Mormente na atualidade, quando se coloca a técnica e a mecanização como ideário a serem atingidos pelas atividades agrícolas, seria imperativo estabelecerse para agricultores familiares - muitos não detentores de poder socioeconômico para engajar-se nesse processo, alternativas focadas em sua (re)existência pela terra e pelo seu trabalho.

Palavras-chave: Capital Social, redes, desenvolvimento, associativismo.

Abstract: This essay seeks to establish a dialogue on the term development and its implications from the perspective of the territorial/rural approach. It also aims to outline a brief panel on social capital, social networks, and partnerships as alternatives to the permanence of rural communities in their territories. The text takes into account the socioeconomic and cultural aspects present in the studies and authors addressed, as well as the process under the aegis of capital, which produces and consumes spaces and cultures that evidence individuals of communities in an invisible rural. Especially nowadays, when technique and mechanization are placed as the assets to be achieved by agricultural activities, it would be imperative to establish itself for family farmers - many not holders of socioeconomic power to engage in this process, alternatives focused at their (re) existence for the land and for their work.

Keywords: Social Capital, networks, development, associativism.

Resumen: Este ensaio busca establecer un diálogo sobre el término desarrollo y sus implicaciones desde la perspectiva del enfoque territorial / rural. También tiene como objetivo esbozar un breve panel sobre capital social, redes sociales y asociaciones como alternativas para la permanencia de las comunidades rurales en sus territorios. El texto tiene en cuenta los aspectos socioeconómicos y culturales presentes en las obras y autores abordados, así como el proceso bajo los auspicios del capital, que produce y consume espacios y culturas que parecen evidenciar individuos de comunidades en 
una zona rural invisible. Principalmente hoy, que si pone la técnica y la mecanización como un ideal para ser alcanzado por las actividades agrícolas, es necesario para establecerse para los agricultores familiares - muchos de los cuales no tienen poder socioeconómico para participar en este proceso, alternativas que focan a su (re) existencia para la tierra y para su trabajo.

Palabras clave: Capital social, redes, desarrollo, asociativismo.

\section{INTRODUÇÃO}

Este ensaio visa promover uma discussão sobre o termo desenvolvimento e seus desdobramentos na abordagem territorial/rural. Na sequência, procura abordar o capital social, as redes sociais e o associativismo como alternativas à permanência das comunidades rurais em seus territórios. O arcabouço teórico-metodológico leva em consideração os aspectos socioeconômico e cultural presentes nas obras abordadas no texto, bem como o processo sob o domínio do capital, que ao mesmo tempo produz e consome espaços e culturas, o que aparenta vislumbrar os indivíduos das comunidades em um rural invisibilizado. Neste sentido, procurou-se analisar as relações simbólico-afetivas (sentimento de pertencimento a determinado grupo social) entre as pessoas e delas para com o ambiente. Ademais, cabe destacar que o tema trata intrinsecamente de relações entre pessoas, e é justamente neste espaço que ocorrem também as relações socioeconômicas, as quais criam a interface entre o território e o seu desenvolvimento em diferentes lugares sejam eles próximos ou não

Não obstante, na atualidade onde se observa que a técnica e a mecanização constituem-se como objetivos a serem alcançados pelas atividades agrícolas, é essencial estabelecer junto aos agricultores familiares - principalmente, porque a maioria deles não possui o poder socioeconômico para envolver-se nesse processo - possibilidades que os permitam permanecer e (re) existir pela terra e pelo seu trabalho. A economia solidária, através do associativismo, das redes sociais e do capital social, pode estabelecer conexões de troca de trabalho e experiência, melhorando assim as condições socioeconômicas e elevando o nível de desenvolvimento local assentado neste território.

Fávaro, Almeida e Fuckner (2011) sugerem que, ao relacionar o desenvolvimento rural na perspectiva territorial é necessário levar em consideração alguns elementos, os quais sejam:

[...] primeiro, é num ambiente cada vez mais competitivo que se dão as chances de sobrevivência das unidades de produção; segundo, a inovação tecnológica continua a ser uma variável-chave para elevar a produtividade da mão de obra e as rendas da população rural; terceiro, a competitividade é um fenômeno sistêmico e depende dos ambientes e dos territórios; quarto, a demanda externa exerce um apelo decisivo sobre as transformações produtivas locais e territoriais; quinto, os vínculos rural-urbanos 
são fundamentais ao desenvolvimento de atividades agrícolas e não agrícolas em um território; sexto, o desenvolvimento institucional tem importância fundamental para o desenvolvimento dos territórios; sétimo, o território não é um espaço físico objetivamente existente, mas uma construção social, isto é, um conjunto de relações sociais que se originam e se expressam em uma identidade e em um sentimento de pertencimento compartilhado por agentes públicos e privados. (Favaro, Almeida \& Fuckner, 2011, p. 113).

Outro fator relevante seria o tipo de abordagem no qual o texto está estruturado. Esta deve levar em consideração dois aspectos, a questão histórico-geográfica da formação territorial, e a dimensão territorial do espaço rural em questão.

\section{PERSPECTIVAS TEÓRICO-CONCEITUAIS A RESPEITO DO DESENVOLVIMENTO}

Iniciamos nossa discussão pelo termo polissêmico 'Desenvolvimento', sujeito a interpretações contraditórias e objeto de disputas nos campos ideológico, econômico, sociocultural, entre outros. Historicamente, o conceito está ligado aos países desenvolvidos e, como política para o desenvolvimento dos países periféricos, traz à tona o paradoxo entre o moderno e o atrasado (Grosfoguel, 2008; Martins, 2011).

Nesta análise não empregamos desenvolvimento como um binômio formado pelo crescimento econômico e pela modernização tecnológica. Souza (1997, p.18) comenta que o desenvolvimento "[...] deve designar um processo de superação de problemas sociais, em cujo âmbito uma sociedade se torna para seus membros, mais justa e legítima". Portanto, o mesmo não deve ser visto somente sob a égide econômica, mas sim numa concepção de desenvolvimento socioespacial, onde deve vislumbrar as necessidades para a superação de dificuldades e para a conquista de condições que oportunizem uma maior satisfação individual e coletiva nos mais variados aspectos, sejam culturais, político-institucionais ou espaços constituintes das relações sociais (cultura, economia e política), bem como o espaço natural.

Nessa linha de raciocínio, Sachs (2000) aponta que finalidades clássicas como lei e ordem ou bem-estar social são invocadas, e em nome do desenvolvimento muitos governos imolam os interesses fundamentais da grande maioria de seu povo. Comenta que as últimas décadas poderiam ser denominadas como era do desenvolvimento, a qual estaria chegando ao final (e afirmando até que seria apropriado ao momento escrever seu obituário). Nesse contexto, segundo o autor, o desenvolvimento tem orientado e guiado as nações emergentes, onde governos e seus cidadãos acreditam que todas as formas de sacrifícios foram, e continuam sendo, justificáveis em prol do desenvolvimento (Sachs, 2000).

Amartya Sen traz a noção de desenvolvimento social, onde os indivíduos seriam dotados de capacidades para gerir seus problemas cotidianos. Segundo o filósofo e economista indiano, os direitos humanos e o desenvolvimento são considerados como expansão dos direitos positivos do ser humano. O mesmo autor em sua obra mais conhecida, Desenvolvimento como liberdade (Sen, 2000), encara o desenvolvimento como um processo de eliminação dos fatores que restringem a liberdade dos indivíduos, restrições que reduzem 
as possibilidades de aproveitar oportunidades de mudar a própria vida. Os fatores mais frequentes de privação da liberdade individual são a fome, a pobreza, a tirania, a falta de moradia digna, de saneamento, e inacessibilidade dos serviços públicos de educação, saúde e segurança.

A falta de liberdade pode ser causada também por fatores políticos como restrições às liberdades civis e políticas, onde governos autoritários e centralizadores não admitem a participação dos cidadãos nas decisões econômicas, sociais e políticas. Essas ressalvas à liberdade reduzem o potencial das pessoas para lutar por melhorias de vida, também reduzem sua autoestima e autoconfiança, fazendo com que as mesmas esperem pouco de si próprias e aceitando pouco dos governantes.

Partindo dessas premissas uma nova linha conceitual foi elaborada para o desenvolvimento rural, focado espacialmente na figura do território, desenvolvendo uma interlocução proveitosa com as instâncias acadêmicas, governamentais e da sociedade civil.

\section{A FACE TERRITORIAL DO DESENVOLVIMENTO}

Estudos e experiências a nível internacional como os da União Europeia e da chamada Terceira Itália com relação ao desenvolvimento territorial a partir de sua base, ou seja, o próprio território, mostraram-se eficazes enquanto estratégias de desenvolvimento territorial/rural a partir de políticas públicas dos Estados centrais ou mesmo supranacionais (Putnam, 1996). Nesta perspectiva, o Estado pode e deve cumprir um papel que extrapola a função de incentivador e articulador de processos de desenvolvimento com base local, sobretudo em territórios rurais deprimidos.

Veiga (2002b) comenta que, no ponto de vista europeu, o desenvolvimento espacial prima por dois objetivos essenciais: o aumento na capacidade competitiva de territórios cuja integração no processo concorrencial é inadequada, e ser fator limitador dos efeitos negativos de uma concorrência fora do controle. Nos dois exemplos, a abordagem espacial procura uma melhor combinação entre competição e cooperação, de forma que o conjunto do território europeu possa atingir um nível ótimo de competitividade, reforçando, ao mesmo tempo, sua coesão econômica e social. Esses objetivos serão atendidos, somente quando os meios forem agrupados em três conjuntos operacionais: a) um sistema policêntrico de cidades, com uma nova relação urbano/rural; b) uma paridade de acesso à infraestrutura e ao conhecimento; c) uma gestão mais prudente das heranças natural e cultural

Segundo Ortega (2007), a experiência da chamada Terceira Itália tornou-se referência paradigmática para a formulação e implantação de estratégias de desenvolvimento local e regional em muitos lugares do mundo. A partir dessa, e de outras experiências bem sucedidas, organizações internacionais (com destaque para o Banco Mundial) também passaram a incentivar as estratégias de desenvolvimento local, recomendando aos Estados nacionais a constituição de arranjos socioprodutivos territoriais como forma de construção de estratégias de desenvolvimento autônomo e endógeno. Assim, as políticas europeias convergiam em cooptar ao desenvolvimento especialmente as regiões com espaços rurais deprimidos e carentes. 


\section{ABORDAGEM TERRITORIAL E SUAS PERSPECTIVAS METODOLÓGICAS}

A justificativa para este recorte encontra-se nas experiências de estudos pautados na perspectiva do desenvolvimento territorial em Saquet (2003), Cunha (2003), Haesbaert (2004), Schneider (2010), Veiga (1997) entre outros, que dentre outras características ressaltam a importância da dimensão histórica na formação de comunidades e desta forma, evidenciam formações heterogêneas que resultam em distintos rurais (ou ruralidades).

Segundo Veiga (1997), ao usar a noção de desenvolvimento rural se está supondo que o desenvolvimento não somente é desigual, mas que essa desigualdade, defasagem, ou descompasso, se manifesta de forma acentuada entre os espaços urbano e rural. Para testar sua hipótese, Veiga examina dados de países "desenvolvidos" buscando comprovar a existência de significativas discrepâncias entre as realidades urbana e rural. Comparando os indicadores sociais e econômicos do Canadá e Estados Unidos constatou que as discrepâncias apresentadas são pequenas, não permitindo afirmar que o desenvolvimento naqueles países não tenha alcançado também os espaços rurais. Seguindo essa linha de pensamento, o conceito de território a partir da abordagem territorial pode responder aos requisitos de equidade, participação social e sustentabilidade, podendo ser adotado também em outras políticas públicas de características semelhantes e propósitos equivalentes (Haesbaert, 2004). Portanto, optou-se por analisar e compreender a porção do espaço onde as relações imateriais e materiais e a compreensão do território partem das relações sociais contidas no seu substrato. Ademais, cabe destacar também que o tema trata intrinsecamente das relações entre pessoas. É neste espaço que ocorrem as relações socioeconômicas (e os conflitos), as quais criam a interdependência entre diferentes lugares do planeta. Assim, na análise a partir da base territorial torna-se cara a utilização do conceito de território para compreender-se o fenômeno e suas implicações, fatores atuantes, bem como os seus vários ritmos.

Outro fator relevante a ser considerado na orientação metodológica é a abordagem histórico-geográfica da formação territorial e da dimensão territorial do espaço rural. Neste contexto, devem ser considerados os processos endógenos de formação do território (Haesbaert, 2004; Raffestin, 2003; Souza, 1995).

Compreende-se que o território sofre modificações ao longo do tempo, nos sentidos linear e coexistente, constituindo-se a partir das relações que nele se estabelece. Portanto, a limitação desta análise não permite exacerba-lo como um todo, mas que se fazem presente nas constituições territoriais de múltiplos espaços rurais. A trajetória histórico-geográfica da distribuição desigual de terras em relação aos grandes estabelecimentos e a concentração nas mãos de poucos, em detrimento do estabelecimento de pequenas unidades de produção baseados no trabalho familiar, contrapõe-se ao longo desse processo nos embates em relação à permanência e resistência da agricultura familiar e a construção de sua identidade.

A concepção de território enquanto processo socioeconômico, político-cultural e natural com bases no trabalho de ajuda mútua, nas trocas, na vida em comunidade, no uso de técnicas não avançadas, contrapõe-se ao processo de inserção da modernização na 
agricultura, a mercadorização de commodities e o êxodo rural. Portanto, são vários aspectos que formam o território da agricultura familiar de forma justaposta ou sobreposta. Desta maneira, a forma de produção, comercialização e as relações de trabalho apontam as comunidades rurais cujo território possui uma identidade centrada na agricultura familiar.

Para Raffestin (2003) o território surge das relações de poder estabelecidas no espaço e no tempo e pode ser sucessivo e superposto. Podendo coexistir outras delimitações territoriais, sejam elas oficiais ou não "[...] o território nessa perspectiva, é um espaço onde se projetou um trabalho, seja energia e informação e que, por consequência revela relações marcadas pelo poder" (Raffestin, 2003, p. 143). Nesse sentido, a sua definição tornou-se um desafio para aqueles que consideram o aporte teórico-metodológico baseado no território, em virtude de se considerar as relações multidimensionais, que se tramam na constituição territorial de forma descontínua (Saquet, 2007). Os dados para caracterizar o território, na maioria das situações, são coletados em fontes oficiais, as quais não individualizam a realidade e os colocam em um bloco não se preocupando com sua escala espacial.

Sendo assim, a própria expressão 'poder', no seu sentido de relações, é obtida das relações políticas, econômicas e culturais que definem o próprio espaço. Dependendo dos interesses a serem atingidos, de suas perspectivas e a variabilidade de escala de abrangência, o poder possibilita a existência de vários territórios.

Segundo Saquet (2003, p. 27):

Se o território é marcado profundamente por relações de poder; relações sociais, evidentemente, se cristalizam no espaço. Se um território pode ter uma reprodução interrompida ou produzida constantemente e, se a existência de um território pressupõe um espaço construído, com homens e relações, um espaço produzido pode não ser um território, no caso de não conter, ou envolver, relações de poder. Se assim for, o espaço geográfico pode ser sinônimo de território, mas não necessariamente [...].

A abordagem territorial, segundo Cunha (2003), deve ser vista inclusiva e deve trazer o desenvolvimento como princípio para o território. Ainda, segundo o mesmo autor, a partir dessa abordagem deve-se desenvolver o lugar para que as pessoas que nele habitem tenham condições para ali viver dignamente.

Como já retratado, o território demanda necessariamente de apropriação ou controle, sendo que as relações de poder nele inseridas vão muito além da delimitação espacial, estando ligadas à identidade e às redes de circulação e comunicação. Nesse sentido, os métodos pelos quais os agricultores lançam mão, expressam de certa maneira as suas territorialidades ligadas às transformações e permanências, em tempos iguais ou não, correspondendo mormente às relações sociais e, dessa forma, espaciais, também expressando a modernidade capitalista e, por conseguinte, produzindo o território

\section{DISCUTINDO O CAPITAL SOCIAL E AS REDES LOCAIS}

Para abordagem das redes (sociais), optou-se por seguir a trilha que analisa suas conexões com o capital social. Neste sentido, o capital social pode ser considerado um conceito recente, mas empregado com êxito no que diz respeito à análise e compreensão 
do desenvolvimento local. Observado a partir de um conjunto de rede formada por indivíduos que cooperam entre si na busca de melhorias sociais, culturais e econômicas, o capital social está ligado a um conjunto de elementos cotidianos, como a camaradagem, a simpatia, a boa vontade, relações entre indivíduos, sua família e a comunidade (Kliksberg, 2000; Bourdieu, 1998; Wolfe, 2002).

Segundo Marteleto e Silva (2004), a partir dos anos 1970 desenvolveram-se estudos mais aplicados quanto à teoria do capital social, que possibilitaram novos conceitos de capital social e desenvolvimento local a partir de redes de relações mútua entre os indivíduos integrantes. Nos anos 1990, os conhecimentos sobre o desenvolvimento e práticas sobre o desenvolvimento local passam por algumas transformações e as desigualdades sociais e econômicas passam a requer mais atenção das correntes e teorias de desenvolvimento. Em 2000, o relatório mundial do Programa das Nações Unidas para o Desenvolvimento (PNUD), salienta a diferença entre a renda individual dos habitantes mais ricos e os mais pobres. Neste contexto, enfatizando a diferença econômica, pode-se questionar questões de ordem social e cultural vistas pelo conceito de capital social.

Neste sentido, o conceito de capital social foi abordado de várias formas, sendo alvo de muitos autores. Bourdieu (1998), remete o capital social à soma de recursos resultantes da integração entre indivíduos e na formação de redes de relações. As transformações que ocorrem dependem dessas redes, da integração entre os indivíduos do grupo, transformando assim, o capital social da comunidade.

Na visão de Putnam (1996, p.177), o capital social é um conjunto de "características da organização social, como confiança, normas e sistemas, que contribuam para aumentar a eficiência da sociedade, facilitando as ações coordenadas".

Desta forma, as próprias raízes históricas, ou seja, as suas trajetórias vão determinar um grau maior ou menor de capital social as sociedades. O dilema dessa questão reside no que Putnam, (1996, p.189), descreve como sendo "as regras do jogo numa sociedade" referindo-se às instituições que comandam de certa forma o desenvolvimento e sugerindo que os sistemas sociais apresentariam uma certa subordinação à trajetória. Expresso de outra maneira, somente pode-se chegar a determinados lugares, , dependendo-se do lugar onde está. (Cunha, 2003).

Estas assertivas levaram Putnam (1996, p. 188) a afirmar que "a subordinação à trajetória pode produzir diferenças duradouras entre o desempenho de duas sociedades, mesmo quando nelas existem instituições formais, recursos, preços relativos e preferências individuais semelhantes".

Enfocando o capital social e a interação dos indivíduos pela formação de redes de relações, Marteleto e Silva (2004, p. 44) descrevem:

O capital social, por sua vez, é definido como as normas, valores, instituições e relacionamentos compartilhados que permitem a cooperação dentro ou entre diferentes grupos sociais. Dessa forma, são dependentes da interação entre, pelo menos, dois indivíduos. Assim, fica evidente a estrutura de redes por trás do conceito de capital social, que passa a ser definido como um recurso da comunidade construído pelas 
suas redes de relações. A construção de redes sociais e a consequente aquisição de capital social estão condicionadas por fatores culturais, políticos e sociais.

Neste aspecto, a participação e a integração dos indivíduos organizados em uma rede de relações sejam elas culturais, sociais, ou de cunho político, partindo do pressuposto do desenvolvimento local em comunidade, parece-nos fazer parte de uma conjuntura.

Segundo Marteleto e Silva (2004), as pessoas vivenciam em seu cotidiano uma rede de dependência que raramente é rompida, essa rede varia de um lugar para o outro, ou seja, caracterizam cada sociedade envolvida de uma forma. O modo que cada indivíduo se comporta é determinado pelas suas relações atuais ou passadas de contato com outras pessoas.

Conforme Kliksberg (2000, p.19), o capital social pode ser visto como um fenômeno subjetivo:

[...] composto por valores e atitudes que influenciam a maneira como as pessoas se relacionam. Inclui confiança, normas de reciprocidade, atitudes e valores que ajudam as pessoas a transcender relacionamentos conflitivos e competitivos para formar relacionamentos cooperativos e de ajuda mútua [...].

Oliveira (2005, p.14) descreve o capital social como sendo o "resultado de estratégias para construir e reproduzir relações sociais duradouras e que estabelecem outras estruturas, normas e relações de confiança de um determinado sistema social". Este sistema pode ser construído por meio da economia solidária, através do associativismo.

\section{O CAPITAL SOCIAL E A ECONOMIA SOLIDÁRIA}

O associativismo, a potencialização das ações coletivas, empregando o conceito de capital social na formação de redes de desenvolvimento de comunidades necessitadas da infraestrutura e melhorias, resulta na economia solidária como resposta de seus objetivos, seu planejamento e execução de suas metas. Neste âmbito Oliveira (2005, p.2) comenta:

Mas, sobretudo, esse cooperativismo serve de campo para os trabalhadores e/ou população de baixa renda, buscar espaços para atuarem dentro de uma orientação que remete ao exercício da cooperação e da solidariedade. Essa cooperação é compreendida como algo que privilegia a autogestão dos negócios e a distribuição coletiva dos resultados da produção também coletiva, exercidas pelos membros das cooperativas populares. Neste sentido, o cooperativismo popular se apresenta como um dos campos onde se pode constatar a formação, a construção e o desenvolvimento de capital social, principalmente se este se apresenta como cimento das redes que são articuladas pelas mais variadas experiências de buscas da minimização da exclusão social e falta de emprego, cujo desenvolvimento tem reforçado a sedimentação da economia solidária no Brasil.

Ainda segundo Oliveira (2005), a economia solidária deve ser compreendida como uma relação de ajuda entre os indivíduos que fazem parte do grupo ou da rede e que estes tenham relações de confiança mútua. Oliveira ainda complementa que à medida que 
determinadas instituições, grupos sociais, agências, assim também como uma associação popular, passam a utilizar este instrumento como uma de suas bases para o desenvolvimento local. Definindo suas estratégias de ação, abre-se um leque interpretativo que aponta ao menos para dois sentidos: o primeiro se trata de um instrumento híbrido e que sobre ele pode ser atribuído sentido próprio conveniente a cada situação, mantendo a independência das ações ordenadas no processo de desenvolvimento; o segundo sugere que o capital social seja relacionado com um dos elementos centrais nos processos do desenvolvimento, pois permite uma ação de reciprocidade entre os grupos, onde se pode visualizar a constituição das redes.

Desta forma, Oliveira (2005) comenta que para que se estruture de fato o associativismo, devem-se observar algumas práticas que se vinculam ao seu exercício, quais sejam, em termos econômicos, os princípios fundamentais adquiridos através da cooperação; em termos administrativos, práticas de definições de interesses que considerem os princípios da autogestão; em termos políticos, buscar a prática de ações coletivas que considerem essenciais o exercício da democracia representativa aliada à democracia participativa dentro das arenas onde são alicerçadas as lutas pelo desenvolvimento e a transformação social e cultural. Assim, as relações são estabelecidas através da confiança, mas devem seguir normas para que a ação seja eficaz e gere futuros resultados recíprocos, pois a partir de então envolvem uma sequência de redes e outros grupos de indivíduos.

O capital social, como diz Oliveira (2005), possui uma ferramenta analítica que fornece características inerentes às ações das organizações nas redes em que atuam. Desta forma a economia solidária é formada através dessas organizações, com um esforço conjunto e ações coletivas buscando um resultado que também se torna coletivo. Portanto, as ações coletivas desenvolvidas pelas organizações, associações populares, e as relações existentes entre elas, podem ser um forte ingrediente para reproduzir o capital social, pois são nas inter-relações e na complementaridade, ou seja, nas ações em rede, que o capital social se fortalece, e forma-se uma economia solidária em comunidade.

Para finalizar, Oliveira (2005) complementa que não é o capital social o único responsável pelo avanço nas interações sociais, mas sim, a relação deste com os demais instrumentos que atuam juntos aos movimentos sociais em rede. Este corolário aponta com vieses para o desenvolvimento territorial/rural.

\section{CONTRIBUIÇÃO DAS REDES PARA O DESENVOLVIMENTO TERRITORIAL}

A rede social enquanto conceito surge na Sociologia e na Antropologia Social nos anos 1930 e 1940 do século passado. Todavia, o termo era utilizado no sentido metafórico, ou seja, os autores não estabeleciam relações entre as redes e o comportamento dos indivíduos que faziam parte dela, muito menos, identificavam características morfológicas úteis para descrição de situações específicas. Foi somente durante a segunda metade do século XX que o conceito ganhou destaque, tornando-se, desde então, praticamente como um novo paradigma dentro das ciências sociais (Portugal, 2007). 
Para entender-se uma estrutura em forma de rede é necessário entender para que essa metodologia foi criada. Nesta linha de raciocínio, Marteleto e Silva (2004), afirmam que as mesmas servem para análise que tem como base as relações entre indivíduos formando uma estrutura de rede, desta forma ajudando na tentativa de compreender a vida social dos grupos envolvidos. Estes autores complementam que as redes são sistemas compostos por "nós", ou seja, conexões entre eles que, nas ciências sociais, são representados por sujeitos sociais (indivíduos, grupos, organizações, etc.).

Para Castells (2005), as redes constituem uma nova forma social para a sociedade e a difusão da lógica de redes transforma de forma substancial a operação e os resultados dos processos de produção e de experiência, poder e cultura. Deste modo redes podem ser conceituadas como:

Rede é um conjunto de nós interconectados. Nós é um ponto no qual uma curva se encontra. Concretamente, o que um nó é depende do tipo de redes concretas de que falamos. [...] Redes são estruturas abertas capazes de expandir de forma ilimitada, integrando novos nós desde que consigam comunicar-se dentro da rede, ou seja, desde que consigam compartilharem os mesmos códigos de comunicação (por exemplo, valores ou objetivos de desempenho). Uma estrutura social com base em redes é um sistema aberto altamente dinâmico suscetível de inovação sem ameaças ao seu equilíbrio. (Castells, 2005, pp. 565-566).

Estas redes podem ser empregadas de diversas formas e pela sua estrutura, Dias (1995, p.148) as descreve como sendo compostas pelas conexões, ou seja, "nós" que funcionam como laços de cooperação e relacionamentos dentro de uma mesma rede ou com um conjunto das demais redes existentes.

Essas redes podem ter um papel econômico a partir do momento que mobilizam ações conjuntas voltadas ao desenvolvimento local. Deste modo utiliza-se a economia solidária para propor que este desenvolvimento pode não ser simplesmente voltado a adquirir maior capital, mas sim, melhorias sociais e culturais a uma comunidade envolvida.

Continuando esta abordagem, Recuero (2005) descreve que uma rede social é definida como um conjunto que abrange dois elementos. O primeiro contempla os atores que podem ser exemplificados por pessoas, instituições ou ainda grupos; Já o segundo comporta as conexões pelos indivíduos que formam uma rede e também deles com as demais redes que podem se formar. Dessa forma Recuero assinala a formação de laços sociais, que são as interações entre as conexões de rede, formando ainda uma interação social, que pode ser a troca de experiências, de cultura, ou seja, as relações estabelecidas por laços de parceria, como é o caso do associativismo.

Esta decantada economia solidária baseia-se não somente na formação do capital - este por si só se torna o resultado - mas, a partir da valorização do ser humano no seu trabalho comunitário de maneira que esses resultados se tornam conjuntos. Uma rede designada associação popular facilmente pode se tornar forte a partir da economia solidária, baseada na confiança, solidariedade e esforços conjuntos, voltados ao capital social e ao desenvolvimento local. 
Como Marteleto e Silva (2004) destacam, o desenvolvimento local é o próprio desenvolvimento das redes estabelecidas.

Criam-se, nas redes formas institucionais próprias associadas aos direitos, responsabilidades e tomadas de decisão. A posição de cada indivíduo na rede depende do capital social e informacional que consiga agregar para si próprio e para o conjunto. A margem da decisão de um indivíduo inserido em uma rede social está sujeita à distribuição do poder, a estrutura de interdependência e de tensões no interior do grupo. É a ocupação de determinadas posições na rede da comunidade, de especial acesso a informações, que determina o sucesso das ações dos indivíduos e seus grupos. (Marteleto \& Silva, 2004, p.46).

As redes também são sistemas institucionalizados, ou seja, com normas internas para seu melhor funcionamento. Uma associação popular é uma rede que contém seus representantes, ou ainda sua presidência. Os indivíduos que integram a rede ocupam posições, estabelecendo assim a estrutura de uma associação. Com o sucesso desta, surge o desenvolvimento territorial/local, seja no campo social, seja no cultural ou no econômico.

Desta maneira Marteleto e Silva (2004) associam a redes e o capital social enfocando a informação para o desenvolvimento:

Na definição de capital social, operam três redes que ampliam o alcance das ações da comunidade: os laços entre os membros da comunidade, isto é, entre pares iguais (capital social de ligação); entre membros da comunidade e representantes de organizações não-governamentais, que ampliam os laços da comunidade (capital social de ponte); entre as lideranças sociais e comunitárias e os representantes das instituições acadêmicas, que abrem os contatos dos agentes das redes locais com representantes que têm autoridade e ligação com instituições públicas (capital social de conexão). (Marteleto \& Silva, 2004, p.47).

Para que os atores locais consigam interagir em instituições como é o caso de uma associação popular e trabalhar de modo a promover o desenvolvimento da comunidade atenuando as diferenças e desigualdades sociais, existem formas intermediárias de coordenação a serem egressas na sociedade. Deste modo as comunidades elaboram formas diferenciadas de enfrentar o que é imposto e superar as dificuldades a partir de movimentos comunitários que envolvam o trabalho associado como uma dessas alternativas.

O desenvolvimento rural consiste, antes de tudo, no fortalecimento do capital social dos territórios, muito mais do que promover o crescimento desta ou daquela atividade econômica. O desafio consiste em dotar as populações vivendo nas áreas rurais das prerrogativas necessárias a que sejam elas as protagonistas centrais da construção dos novos territórios. (Fávaro, Almeida, \& Fuckner, 2011, p. 114).

Colocam-se então, estas alternativas no intuito de promover a melhora da forma de vida da população contribuindo de maneira significativa para uma mudança maior na qual se engloba todo contexto no qual a comunidade rural está inserida. 
Nesta linha de raciocínio o desenvolvimento local deve ser pensado enquanto projeto de transformação social, construído social e territorialmente interagindo entre os atores sociais ali envolvidos. Assim, Oliveira (2005, p.26) complementa:

Se as cooperativas podem ser consideradas como unidades de produção de capital social e se elas podem ser consideradas como unidades de sustentação da economia solidária. Estas observações se tornam importantes, pois se permite, através delas, enxergar o papel que as cooperativas populares desempenham, por exemplo, em programas de desenvolvimento. [...] E, por outro lado, por outro lado, permite observar o grau de contribuição que essas cooperativas estão tendo no sentido de possibilitar aos seus cooperados, uma nova postura econômica e política.

Salienta ainda Oliveira que as cooperativas, bem como as associações populares demonstram uma força relativa, mas perceptível no sentido de corroborar no processo de minimização do desemprego, sendo uma alternativa para trabalhadores familiares rurais, e ainda, torna-se uma vertente contra a exclusão social, favorecendo o trabalho comunitário participativo. Deste modo, este processo favorece a produção e reprodução do capital social e sustenta a economia solidária.

\section{CONSIDERAÇÕES FINAIS}

Por todo o contexto vislumbrado, consideramos que o termo desenvolvimento e suas diversas elucubrações dissolvem-se em detrimento da evidente impossibilidade de impor um modelo cultural padronizado para o mundo, obstáculos estruturais impossibilitam a materialização mundial dessas metas, por mais que o desenvolvimento se apresente como sendo o ideal a ser seguido.

Fracassado como aparelhamento de melhoria social, o desenvolvimento considerado sob o prisma do crescimento econômico consolida-se como meio de controle, dominando os meios de produção e suas técnicas, difundido em um discurso obscuro, atrelando erroneamente progresso e melhoria ao desenvolvimento. Isto acaba por restringir, dentro de uma reprodução da ordem social capitalista, os efeitos positivos para uma minoria.

Posto isto, concordamos que o desenvolvimento deve ser pensado enquanto projeto de transformação social, construído social e territorialmente interagindo entre os atores sociais ali envolvidos (Souza,1995).

Finalmente acreditamos, alicerçado nas ideias dos autores e em suas obras retratadas, que é possível estabelecer um diálogo entre o desenvolvimento territorial/rural e os conceitos empreendidos no presente trabalho. A partir da perspectiva da abordagem territorial, do capital social e das redes sociais, é possível estabelecer-se uma rede para o desenvolvimento/rural na sua dimensão territorial dentro da multidimensionalidade escalar, levando-se em consideração a realidade e permanência das comunidades rurais no meio rural em que residem e trabalham. 


\section{REFERÊNCIAS}

Bourdieu, Pierre (1998). O capital social - notas provisórias. In Afrânio Catani, \& Maria A. Nogueira (Orgs) Escritos de Educação. (pp.65-69). Petrópolis: Vozes.

Castells, Manuel (2005). A Sociedade em Rede. A era da Informação: Economia, Sociedade e Cultura. 8a ed. São Paulo: Paz e Terra.

Cunha, Luiz A.G. (2003). Paraná: desenvolvimento rural e desenvolvimento territorial: o caso do Paraná tradicional. (Tese de Doutorado). Universidade Federal do Rio de Janeiro, UFRJ, Rio de Janeiro, RJ, Brasil.

Dias, Leila C. (1995). Redes: Emergência e organização. In Iná E. Castro, Paulo Cesar da Costa Gomes, \& Roberto Lobato Corrêa (Eds). Geografia: conceitos e temas. (pp. 140-164). Rio de Janeiro: Bertrand Brasil.

Fávaro, Jorge L., Almeida, Benedito L., \& Fuckner, Marcus (2011). Territórios rurais do Paraná - uma proposta de gestão para o desenvolvimento. In. Nilson Fraga (Org.). Territórios Paranaenses. (pp. 109-133). Florianópolis: Insular.

Grosfoguel, Ramón (2008). Developmentalism, modernity and dependency theory in Latin America. In Mabel Maranã, Enrique Dussel, \& Carlos Jáuregui (Eds.) Coloniality at large. Latin America and the postcolonial debate. (pp. 115-147). Durham: Duke University Press.

Haesbaert, Rogério (2004). O mito da desterritorialização. Rio de Janeiro: Bertrand Brasil.

Kliksberg, Bernardo (2000). El rol del capital social y de la cultura em processo de desarrollo. In: Bernardo Kliksberg, \& Luciano Tomassini (Orgs). Capital social y cultura: claves estratégicas para el desarrollo. (pp. 1550). Buenos Aires: Fondo de Cultura Económica.

Marteleto, Regina M., \& Silva, Antônio Braz de Oliveira (2004). Redes e capital social: o enfoque da informação para o desenvolvimento local. Ciência da Informação, 33(3), 41-49.

Martins, Carlos E. (2011). Dependência, neoliberalismo e novos padrões de desenvolvimento na América Latina. In Carlos Eduardo Martins: Globalização, dependência e neoliberalismo na América Latina. (cap. 7, pp. 337 -371 ) Rio de Janeiro: Bom Tempo.

Oliveira, Benedito A.M. (2005). O capital social nas Cooperativas Populares e suas relações com a Economia Solidária. GT 02 - Desenvolvimento, Trabalho e Gestão. $3^{\text {a }}$ Sessão: Autogestão, cooperativismo e economia solidária. Anais do Congresso Brasileiro de Sociologia. Belo Horizonte, MG, Brasil, 12. Recuperado de http:// www.sbsociologia.com.br/portal/index.php?option=com_docman\&task=cat_view\&gid=58\&Itemid=171

Ortega, Antonio C. (2007). Desenvolvimento territorial rural no Brasil: limites e potencialidades dos CONSADs. Revista de Economia e Sociologia Rural, 45(2): 275-300.

Portugal, Sílvia (2007). Contributos para uma discussão do conceito de rede na teoria sociológica. Oficina de CES, 271:1-36. Recuperado de https://ces.uc.pt/pt/publicacoes/outras-publicacoes-e-colecoes/oficinado-ces/numeros/oficina-271.

Programa das Nações Unidas para o Desenvolvimento. Relatório do Desenvolvimento Humano 2000. Recuperado de http://www.br.undp.org/content/brazil/pt/home/library/idh/relatorios-dedesenvolvimento-humano/relatorio-do-desenvolvimento-humano-2000.html

Putnam, Robert (1996). Comunidade e democracia: a experiência da Itália Moderna. Rio de Janeiro: FGV.

Raffestin, Claude (2003). Por uma Geografia do Poder. São Paulo: Ática.

Recuero, Raquel da C. (2005). Um estudo do capital social gerado a partir de redes sociais no Orkut e nos Weblogs. Revista FAMECOS, 12(28):88-106. DOI: 10.15448/1980-3729.2005.28.3340

Sachs, Wolfgang (2000). Meio Ambiente In Wolfgang Sachs. Dicionário do desenvolvimento: guia para o conhecimento como poder. Petrópolis: Vozes.

Saquet, Marcos (2003). A. Os tempos e os territórios da colonização italiana: O desenvolvimento econômico na Colônia Silveira Martins (RS). Porto Alegre: Edições EST.

Saquet, Marcos (2007). A. As diferentes abordagens do território e a apreensão. Geosul, 22(43):55-76. 
Schneider, Sergio (2010). Situando o desenvolvimento rural no Brasil: o contexto e as questões em debate. Revista de Economia Política, 30(3):511-531.

Sen, Amartya (2000). Desenvolvimento como liberdade. São Paulo: Companhia das Letras.

Souza, Marcelo J.L. (1995). O território: sobre espaço e poder, autonomia e desenvolvimento. In Iná. E. Castro, Paulo Cesar da Costa Gomes, \& Roberto Lobato Corrêa (Eds). Geografia: conceitos e temas. (pp. 77116). Rio de Janeiro: Bertrand Brasil.

Souza, Marcelo J.L (1997) Como pode o turismo contribuir para o desenvolvimento local? In: A.B. Rodrigues (Org.). Turismo e Desenvolvimento Local. (pp. 17-22). São Paulo: HUCITEC.

Veiga, José E. (1997). Perspectivas nacionais do desenvolvimento rural. In Shigeo.Shiki, José G. Silva, \& Antonio C. Ortega. Agricultura, Meio Ambiente e Sustentabilidade do Cerrado Brasileiro (pp. 101-118). Uberlândia: UFU/CNPq/FAPEMIG.

Veiga, José E. (2002a). Cidades Imaginárias. O Brasil é mais rural do que se calcula. Campinas: Autores Associados.

Veiga, José E. (2002b). A face territorial do desenvolvimento. Revista Internacional de Desenvolvimento Local, 3(5): 5-19.

Wolfe, David A. (2002). Social Capital and Cluster Development in Learning Regions. In J. Adam Holbrook, \& David A. Wolfe (Eds.) Knowledge, Clusters and Regional Innovation: Economic Development in Canada. Montreal: McGill-Queen's University Press for the School of Policy Studies.

Data de submissão: 15/mar./2020

Data de aceite: 09/jul./2020 